\title{
Coupling of Fenton and Biological Processes for Pulp Bleaching Wastewater Treatment
}

\author{
João Peres Ribeiro', Carolina Pedrosa Morim¹, Flávio Castro Silva1, Maria Isabel Nunes ${ }^{1}$ \\ ${ }^{1}$ Department of Environment and Planning and CESAM - Centre for Environmental and Marine Studies, University of \\ Aveiro \\ Campus Universitário de Santiago, Aveiro, Portugal \\ joaoperes@ua.pt ; carolinapedrosamorim@ua.pt ; flavio.silva@ua.pt ; isanunes@ua.pt
}

\begin{abstract}
In this work, Fenton and biological aerobic processes were sequentially coupled for real pulp bleaching wastewater treatment. Biological treatment was conducted on raw pulp bleaching wastewater and on Fenton-treated wastewater, to search for a suitable treatment layout allowing for COD and recalcitrant pollution abatement. Biological treatment was conducted in $0.5 \mathrm{~L}$ glass flasks, under magnetic stirring and temperature of $20^{\circ} \mathrm{C}$. A ratio of COD:N:P = 100:7:1 was used, with initial concentration of volatile suspended solids of $3 \mathrm{~g} \cdot \mathrm{L}^{-1}$. Different initial loads as soluble COD were tested. Fenton process experiments $\left(0.5 \mathrm{~L}\right.$ batch) were conducted under natural wastewater $\mathrm{pH}$ of $2.48 \pm 0.20,60{ }^{\circ} \mathrm{C}$, $6.0 \mathrm{mM}$ of $\mathrm{Fe}^{2+}$ (as $\mathrm{FeSO}_{4} .7 \mathrm{H}_{2} \mathrm{O}$ ) and $139 \mathrm{mM}$ of $\mathrm{H}_{2} \mathrm{O}_{2}$. The combination of processes successfully removed COD and AOX from both raw pulp bleaching wastewater and Fenton-treated wastewater, achieving the highest removals with the highest initial organic loads. Maximum removal of AOX of $94 \%$ was achieved in the wastewater undergoing Fenton treatment followed by biological treatment, while the highest removal of COD was achieved in the wastewater submitted to biological treatment followed by the Fenton process, $84 \%$, with a final concentration of $0.48 \mathrm{~g}_{\mathrm{s}} \mathrm{COD} \cdot \mathrm{L}^{-1}$.
\end{abstract}

Keywords: Fenton, Biological treatment, AOX, COD, Pulp bleaching wastewater

\section{Introduction}

Biological aerobic treatment aims at the oxygen-assisted degradation of organic load by microorganisms, producing production of biomass, carbon dioxide and water [1]. The mechanism consists in three steps: adsorption by contact between the compounds present in the wastewater with the microorganisms; metabolism, which is the degradation of the contaminants through biochemical reactions; flocculation, consisting in the agglomeration of the biological material, yielding a settable sludge [2]. This process targets primarily the removal of $\mathrm{COD}$ and $\mathrm{BOD}_{5}$ from the wastewater, however it does not present a high efficiency in the decomposition of recalcitrant compounds [2]. Fenton process is a widely studied method for wastewater treatment, recognized for its fast and effective abatement of recalcitrant pollution. It is based on the catalytic $\left(\mathrm{Fe}^{2+}\right)$ dissociation of $\mathrm{H}_{2} \mathrm{O}_{2}$ into hydroxyl radicals $\left({ }^{\bullet} \mathrm{OH}\right)$, which non-selectively oxidizes organic compounds [3]-[5].

Brink, Sheridan and Harding (2020) [6] used a combination of aerated biological treatment, in a moving bed biofilm reactor, followed by Fenton experiments run in batch reactors, for the treatment of pulp and paper industry wastewater. A 55 $\%$ removal of COD was achieved under hydraulic retention time (HRT) of $24 \mathrm{~h}$, using and organic loading rate ranging 4.52 $\mathrm{kg} \mathrm{COD} \cdot \mathrm{m}^{-3} \cdot \mathrm{d}^{-1}$ to $9.04 \mathrm{~kg} \mathrm{COD} \cdot \mathrm{m}^{-3} \cdot \mathrm{d}^{-1}, 3.1 \mathrm{mg} \cdot \mathrm{L}^{-1}$ of dissolved oxygen, and $\mathrm{pH}$ ranging 8.0 to 8.5 . The Fenton process was applied to the wastewater under $14.55 \mathrm{mM}$ of $\mathrm{H}_{2} \mathrm{O}_{2}, 17.91 \mathrm{mM}$ of $\mathrm{Fe}^{2+}$ and $\mathrm{pH}=3.33$, with an additional $53.73 \%$ degradation of COD after 60 min of treatment. Abedinzadeh et al. (2018) [7] used a sequential batch reactor followed by the Fenton treatment for the removal of COD from a pulp and paper wastewater. The SBR worked under $2 \mathrm{mg} \mathrm{O} \cdot \mathrm{L}^{-1}$, VSS (volatile suspended solids) $=3 \mathrm{~g} \cdot \mathrm{L}^{-1}$, solids retention time of 20 days and HRT of $24 \mathrm{~h}$. Removal of COD and colour of $74.8 \%$ and $58.3 \%$ was achieved, respectively. The combination of this treatment with the Fenton process $(6.0$ $\mathrm{mM} \mathrm{H}_{2} \mathrm{O}_{2}$ and $3.0 \mathrm{mM} \mathrm{Fe}{ }^{2+}$ ) led to an overall COD and colour removal of $98 \%$ and $94 \%$, respectively.

This work aimed at tackling one major issue in this field of research: how to include in wastewater treatment plants a step that effectively removes recalcitrant compounds, without hindering biological reactor's activity. Biological treatment 
was conducted on raw pulp bleaching wastewater and on Fenton-treated pulp bleaching wastewater, to search for a suitable treatment layout allowing for COD and adsorbable organic halides (AOX) abatement.

\section{Materials and Methods}

The pulp bleaching wastewater $-\mathrm{D}_{0}$ stream, after the first chlorine dioxide bleaching stage - was collected at a Portuguese pulp and paper industry that produces kraft pulp, mainly from Eucalyptus globulus. Biological sludge was collected at the wastewater treatment plant of the same industry. Biological aerobic treatment and Fenton process were coupled sequentially to remove COD and AOX from the collected pulp bleaching wastewater, according to the treatment layouts presented in Figure 1.

(a)

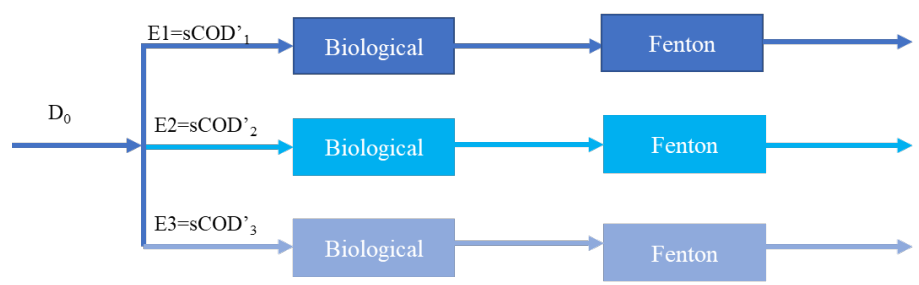

(b)

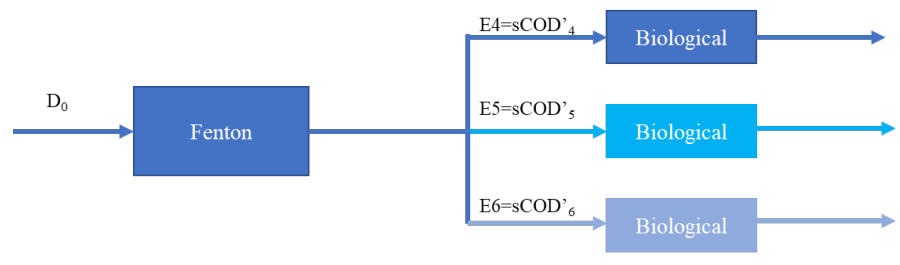

Figure 1. Schematic of the experimental planning for the combination of: (a) biological treatment followed by Fenton process and (b) combination of the Fenton process followed by biological treatment.

Biological treatment was conducted in $0.5 \mathrm{~L}$ glass flasks, under magnetic stirring, at $20^{\circ} \mathrm{C}$, for five days. $\mathrm{pH}$ was adjusted to $6.5-7.5$ at the beginning of the treatment, using $2.0 \mathrm{M} \mathrm{NaOH}$ and/or $32.5 \% \mathrm{HNO}_{3}$. Nutrients $\mathrm{N}$ and $\mathrm{P}$ were added to the flasks as $10 \mathrm{~g} \cdot \mathrm{L}^{-1} \mathrm{NH}_{4} \mathrm{Cl}$ and $5 \mathrm{~g} \cdot \mathrm{L}^{-1} \mathrm{KH}_{2} \mathrm{PO}_{4}$, respectively, to ensure for COD:N:P of 100:7:1. Initial VV load of $3 \mathrm{~g}$ VSS $\cdot \mathrm{L}^{-1}$ was used. Wastewater was diluted to study the effect that initial organic load and/or the presence of inhibitory chemicals (for microbiological activity) could have on treatment efficiency. Dilution factors of 2.6 (E1 and E4), 1.7 (E2 and E5) and 1 (E3 and E6 - undiluted) were applied.

Fenton process experiments $(0.5 \mathrm{~L}$ batch) were conducted under wastewater $\mathrm{pH}$ of $2.48 \pm 0.20$, which favours Fenton's effectiveness [5]. Regarding temperature, Fenton experiments were conducted at $60 \pm 2{ }^{\circ} \mathrm{C}$, which is the natural temperature of this wastewater stream. When the wastewater reached the desired temperature, $6.0 \mathrm{mM}$ of $\mathrm{Fe}^{2+}$ (as $\left.\mathrm{FeSO}_{4} .7 \mathrm{H}_{2} \mathrm{O}\right)$ and $139 \mathrm{mM}$ of $\mathrm{H}_{2} \mathrm{O}_{2}(30 \% \mathrm{w} / \mathrm{v})$ were added. These operating conditions aimed at maximising AOX removal, as described elsewhere [8]. Magnetic stirring was maintained throughout the experiments at $200 \mathrm{rpm}$. Results previously published showed that AOX removal did not increase significantly with treatment time ranging $10-30$ minutes [9], therefore Fenton experiments conducted in this work lasted for 10 minutes.

COD and AOX were measured according to Standard Methods 5220D and EN 16166:2012, ISO 9562:2004 and EPA Method 1650C [10]. Measurements were performed in the raw wastewater, and after each treatment step.

\section{Results and Discussion}

\subsection{Biological Treatment Followed By Fenton Process}

The dilution factors applied to raw pulp bleaching wastewater aimed at initial ${ }_{\mathrm{s}} \mathrm{COD} \cdot \mathrm{L}^{-1}$ ranging $1.50-3.00$. Experimental verification was performed, showing that initial COD loads for E1, E2 and E3 experiments were $1.59 \mathrm{~g}$ ${ }_{\mathrm{s}} \mathrm{COD} \cdot \mathrm{L}^{-1}, 2.07 \mathrm{~g}{ }_{\mathrm{s}} \mathrm{COD} \cdot \mathrm{L}^{-1}$ and $2.99 \mathrm{~g}{ }_{\mathrm{s}} \mathrm{COD} \cdot \mathrm{L}^{-1}$, respectively. After biological treatment, $0.74 \mathrm{~g}{ }_{\mathrm{s}} \mathrm{COD} \cdot \mathrm{L}^{-1}, 0.96 \mathrm{~g}$ ${ }_{s} \mathrm{COD} \cdot \mathrm{L}^{-1}$ and $1.18 \mathrm{~g}{ }_{\mathrm{s}} \mathrm{COD} \cdot \mathrm{L}^{-1}$ were registered in those conditions, corresponding to removal of $54 \%, 54 \%$ and $61 \%$, respectively. These results show slightly higher removal rate with increasing initial organic load, proving the suitability of biological aerobic process to treat pulp bleaching wastewater. Additionally, AOX removal of $66 \%, 64 \%$ and $58 \%$ were attained in conditions E1, E2 and E3, corresponding to final values of 5.33, 7.59 and $12.63 \mathrm{mg} \mathrm{AOX} \cdot \mathrm{L}^{-1}$, respectively. As AOX acts as a co-substrate, with a higher increase in COD in the wastewater, leads to a decrease in its removal rates. The application of Fenton process to the biologically treated wastewater led to additional COD removal 
of $77 \%, 64 \%$ and $59 \%$, and AOX removal of $74 \%, 81 \%$ and $76 \%$, for the conditions E1, E2 and E3, respectively. Therefore, after the combined treatment, final concentrations of $0.17 \mathrm{~g}_{\mathrm{s}} \mathrm{COD} \cdot \mathrm{L}^{-1}$ and $1.40 \mathrm{mg} \mathrm{AOX} \cdot \mathrm{L}^{-1}, 0.35 \mathrm{~g} \mathrm{~s}_{\mathrm{S}} \mathrm{COD} \cdot \mathrm{L}^{-1}$ and 1 and $2.44 \mathrm{mg} \mathrm{AOX} \cdot \mathrm{L}^{-1}, 0.48 \mathrm{~g}{ }_{\mathrm{s}} \mathrm{COD} \cdot \mathrm{L}^{-1}$ and $3.00 \mathrm{mg} \mathrm{AOX} \cdot \mathrm{L}^{-1}$, were achieved for the conditions E1, E2 and E3, respectively. These results are depicted in Figure 2.

(a)

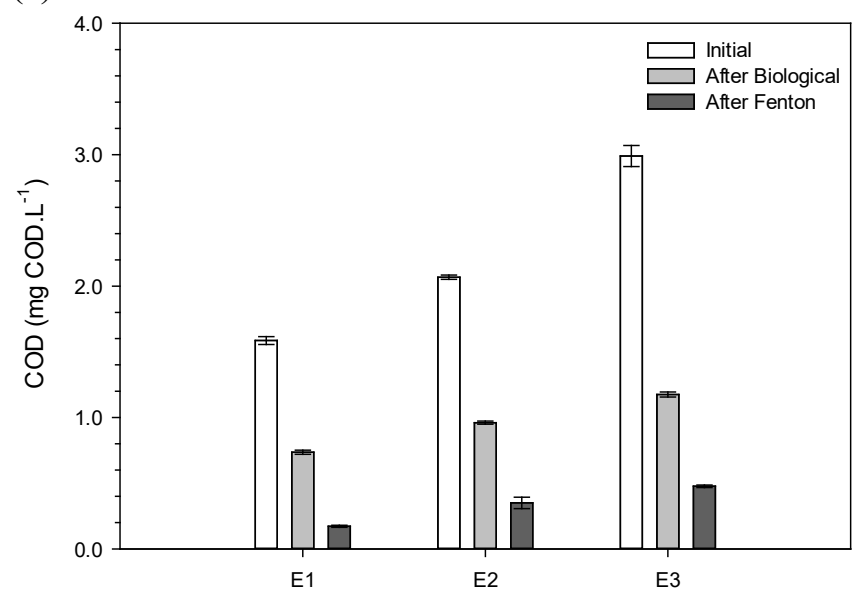

(c)

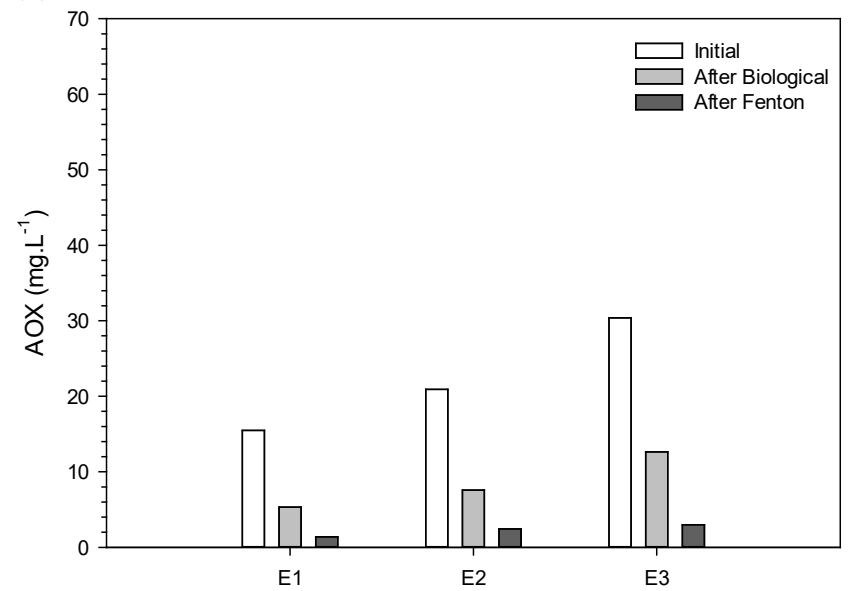

(b)

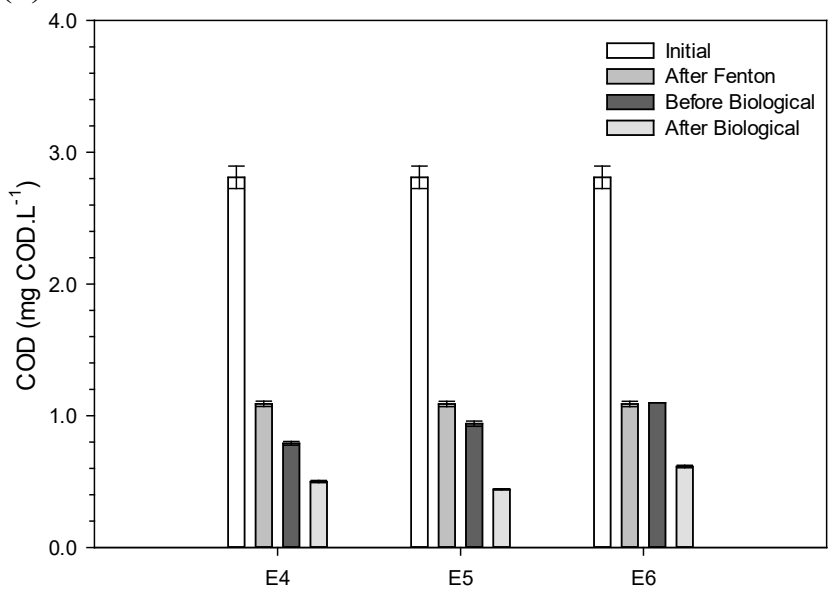

(d)

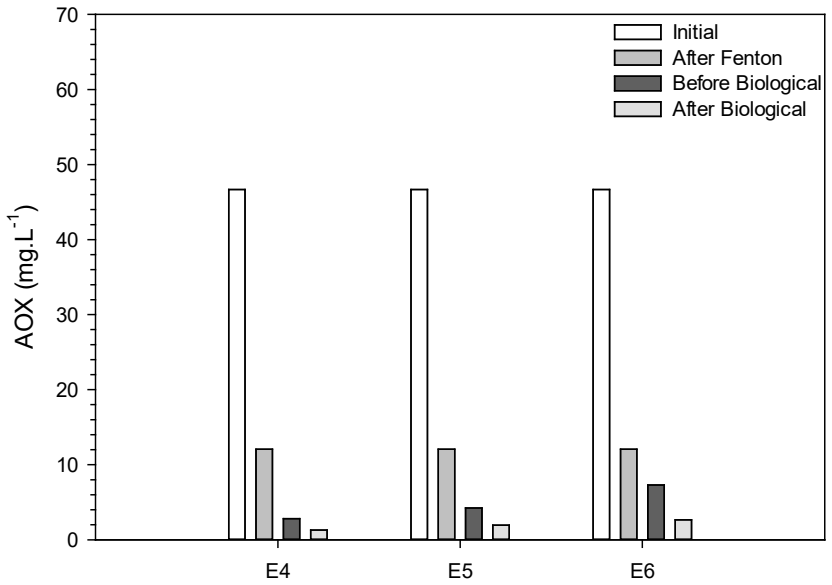

Figure 2. Concentration of: (a) COD at different stages of biological treatment followed by Fenton process; (b) COD at different stages of Fenton process followed by biological treatment; (c) AOX at different stages of biological treatment followed by Fenton process; (d) AOX at different stages of Fenton process followed by biological treatment.

\subsection{Fenton process followed by biological treatment}

Fenton process removed $66 \%$ COD from the raw pulp bleaching wastewater, corresponding to final concentration of $1.09 \mathrm{~g} \mathrm{COD} \cdot \mathrm{L}^{-1}$. The subsequent dilution of the Fenton-treated wastewater was made to evaluate the presence of products resulting from the Fenton process that may act as inhibitors of microbiological activity. The same dilution factors were applied as before, leading to initial organic loads of $0.79 \mathrm{~g}{ }_{\mathrm{s}} \mathrm{COD} \cdot \mathrm{L}^{-1}, 0.94 \mathrm{~g}{ }_{\mathrm{s}} \mathrm{COD} \cdot \mathrm{L}^{-1}$ and $1.10 \mathrm{~g}{ }_{\mathrm{s}} \mathrm{COD} \cdot \mathrm{L}^{-1}$, for the experiments E4, E5 and E6, respectively.

Subsequent biological treatment achieved COD removal of $36 \%, 53 \%$ and $44 \%$, for experiments E4, E5 and E6, corresponding to final concentration of $0.50 \mathrm{~g}{ }_{\mathrm{s}} \mathrm{COD} \cdot \mathrm{L}^{-1}, 0.44 \mathrm{~g} \mathrm{~s}_{\mathrm{s}} \mathrm{COD} \cdot \mathrm{L}^{-1}$ and $0.61 \mathrm{~g} \mathrm{~s}_{\mathrm{s}} \mathrm{COD} \cdot \mathrm{L}^{-1}$, respectively. This treatment 
also removed $54 \%, 54 \%$ and $64 \%$ of AOX, achieving final concentrations of $1.29 \mathrm{mg} \mathrm{AOX} \cdot \mathrm{L}^{-1}, 1.95 \mathrm{mg} \mathrm{AOX} \cdot \mathrm{L}^{-1}$ and $2.66 \mathrm{mg} \mathrm{AOX} \cdot \mathrm{L}^{-1}$, in experiments E4, E5 and E6, respectively. These results are depicted in Figure 2.

\section{Conclusions}

Polluting load of the wastewater stream generated in the bleaching stage of the pulp production process was decreased by the combination of biological aerobic and Fenton processes.

The application of different initial organic loads allowed for the ascertainment of the biological sludge capacity to adapt and degrade both raw wastewater and chemically treated wastewater, with no apparent inhibition of microorganisms' activity. In fact, higher initial loads favoured the removal of COD and AOX, showing that the biological sludge was able to cope with high concentration of recalcitrant organic compounds and chemical products from Fenton reactions.

When comparing the two treatment layouts applied to undiluted wastewater (conditions E3 and E6), it was possible to conclude that the combined treatment yielded similar results, regardless of the adopted sequence: when Biological process was followed by Fenton process (E3), overall COD and AOX removal of $84 \%$ and $90 \%$ was achieved, corresponding to $0.48 \mathrm{~g}{ }_{\mathrm{s}} \mathrm{COD} \cdot \mathrm{L}^{-1}$ and $3.00 \mathrm{mg} \mathrm{AOX} \cdot \mathrm{L}^{-1}$ in the treated wastewater; when Fenton process was followed by biological treatment (E6), overall COD and AOX removal of $78 \%$ and $94 \%$ was achieved, corresponding to $0.61 \mathrm{~g}$ ${ }_{s} \mathrm{COD} \cdot \mathrm{L}^{-1}$ and $2.66 \mathrm{mg} \mathrm{AOX} \cdot \mathrm{L}^{-1}$ in the treated wastewater.

\section{Acknowledgements}

Thanks are due to FCT/MCTES for the financial support to CESAM (UIDP/50017/2020 + UIDB/50017/2020), through national funds. J. P. Ribeiro acknowledges FCT - Fundação para a Ciência e a Tecnologia, I.P. for his PhD Grant (SFRH/BD/141133/2018).

\section{References}

[1] M. Suhr, G. Klein, I. Kourti, M.R. Gonzalo, G.G. Santonja, S. Roudier and L.D. Sancho, "Best Available Techniques (BAT) Reference Document for the Production of Pulp, Paper and Board," 2015.

[2] M. A. Hubbe, J. R. Metts, D. Hermosilla, M.Angeles-Blanco, L. Yerushalmi, F. Haghighat, P. Lindholm-Lehto, Z. Khodaparast, M. Kamali and A. Elliott, "Wastewater treatment and reclamation: A review of pulp and paper industry practices and opportunities," BioResources, vol. 11, no. 3, pp. 7953-8091, 2016.

[3] A. Babuponnusami and K. Muthukumar, "A review on Fenton and improvements to the Fenton process for wastewater treatment,” J. Environ. Chem. Eng., vol. 2, pp. 557-572, 2014.

[4] A. Brink, C. M. Sheridan, and K. G. Harding, "The Fenton oxidation of biologically treated paper and pulp mill effluents: A performance and kinetic study," Process Saf. Environ. Prot., vol. 107, pp. 206-215, 2017.

[5] J. P. Ribeiro and M. I. Nunes, "Recent trends and developments in Fenton processes for industrial wastewater treatment - A critical review," Environ. Res., vol. 197, no. 110957, 2021.

[6] A. Brink, C. Sheridan, and K. Harding, "Combined biological and advance oxidation processes for paper and pulp ef fl uent treatment," vol. 25, no. 2018, pp. 116-122, 2020.

[7] N. Abedinzadeh, M. Shariat, S. M. Monavari, and A. Pendashteh, "Evaluation of color and COD removal by Fenton from biologically (SBR) pre-treated pulp and paper wastewater," Process Saf. Environ. Prot., vol. 116, pp. 82-91, 2018.

[8] J. P. Ribeiro, C. C. Marques, I. Portugal, and M. I. Nunes, "Fenton processes for AOX removal from a kraft pulp bleaching industrial wastewater: Optimisation of operating conditions and cost assessment," J. Environ. Chem. Eng., vol. 8, no. 4, p. 104032, 2020.

[9] J. P. Ribeiro, C. C. Marques, I. Portugal, and M. I. Nunes, "AOX removal from pulp and paper wastewater by Fenton and photo-Fenton processes: A real case-study," Energy Reports, vol. 6, 2020.

[10] A. Greenberg, L. Clesceri, and A. Eaton, Eds., Standard methods for the examination of water and wastewater, 20th ed. Baltimore: American Public Health Association; American Water Works Association; Water Environment Federation, 1999. 